\title{
Status of the ITER Ion Cyclotron H\&CD
}

\author{
Bertrand Beaumont ${ }^{\mathrm{a},{ }^{,}}$, Rohit Agarwal ${ }^{\mathrm{b}}$, Tania Alonzo Montemayor ${ }^{\mathrm{e}}$, Rohit Anand ${ }^{\mathrm{b}}, \mathrm{P} \mathrm{Ajesh}^{\mathrm{b}}$, Francois Calarco $^{\mathrm{a}}$ \\ Hrushikesh Dalicha ${ }^{b}$, 'Craig Deibele ${ }^{\mathrm{c}}$, Nicolas Ferrigno ${ }^{\dagger}$, Thibault Gassmann ${ }^{\mathrm{a}}$, Davide Kleiner ${ }^{\mathrm{d}}$, Richard Hanks ${ }^{\mathrm{c}}$, \\ JVS Hari ${ }^{\mathrm{b}}$, Richard Goulding ${ }^{\mathrm{c}}$, Margaret Graham ${ }^{\mathrm{a}}$, Akhil Jha ${ }^{\mathrm{b}}$, Fabienne Kazarian ${ }^{\mathrm{a}}$, Philippe Lamalle ${ }^{\mathrm{a}}$, Harsha \\ Machchhar $^{\mathrm{b}}$, Mike McCarthy ${ }^{\mathrm{c}}$, Mark Middendorf $^{\mathrm{c}}$, Kartik Mohan ${ }^{\mathrm{b}}$, Aparajita Mukherjee ${ }^{\mathrm{b}}$, Amit Patel $^{\mathrm{b}}$, Manoj \\ Patel $^{\mathrm{b}}$, Hriday Patel ${ }^{\mathrm{b}}$, Kumar Rajnish $^{\mathrm{b}}$, David Rasmussen ${ }^{\mathrm{c}}$, Dipal Soni ${ }^{\mathrm{b}}$, Manoj Singh $^{\mathrm{b}}$, Narinder Pal Singh ${ }^{\mathrm{b}}$, \\ Raghuraj Singh ${ }^{\mathrm{b}}$, Gajendra Suthar ${ }^{\mathrm{b}}$, Rajesh Trivedi ${ }^{\mathrm{b}}$, Roberto Sanabriac, Roberta Sartori ${ }^{\mathrm{d}}$, Michael Smith $^{\mathrm{c}}$, \\ David Swain ${ }^{\mathrm{c}}$, Pareshkumar Vasava ${ }^{\mathrm{b}}$, Sriprakash Verma ${ }^{\mathrm{b}}$, Kurt Vetter ${ }^{\mathrm{c}}$, Paul Wright $^{\mathrm{c}}$ \\ a ITER Organization, Route de Vinon sur Verdon, CS 90 046, 13067 St Paul Lez Durance, France \\ ${ }^{b}$ ITER-India, Institute for Plasma Research, Bhat, Gandhinagar - 382428, India \\ ${ }^{c}$ US ITER Project Office, ORNL, 055 Commerce Park, PO Box 2008, Oak Ridge, TN 37831, USA \\ ${ }^{d}$ Fusion for Energy, C/ Josep Pla 2, Torres Diagonal Litoral-B3,E-08019 Barcelona - Spain \\ ${ }^{e}$ Solution F, Allée du Verdon, 13770 Venelles, France \\ ${ }^{f}$ Ametra, Z.I. Les Cabassols, 13770 Venelles, France
}

\begin{abstract}
The ITER Ion Cyclotron Heating and Current Drive system (IC H\&CD) is designed to deliver $20 \mathrm{MW}$ to a broad range of plasma scenarios between 40 and $55 \mathrm{MHz}$, during very long pulses. It consists of two broadband equatorial port plug antennas, their pre-matching and matching systems, transmission lines, Radio Frequency (RF) Sources and High Voltage Power Supplies. The overall project schedule has been revised and agreed by ITER Council; it re-integrates the second antenna and its power supplies in construction baseline and sets the dates for progressive installation with DT phase planned in 2035. Recent progress on ICRF subsystems is reported, covering design evolution, qualification of test articles and specific R\&D results in domestic agencies, suppliers, associated laboratories and IO.
\end{abstract}

\section{Introduction}

A revised overall project schedule has been presented at the ITER Council in November 2016. This schedule is defining the steps between now and the start of DT operation in 2035, with progressive installation of the basic machine and its equipment. The specific targets for the ICRF system, compatible with the development of the ITER Research Plan have been presented. The Council has also requested to evaluate how to anticipate installation and commissioning of part of the ICRF system.

Meanwhile, the $R \& D$ is progressing well for the $R F$ sources and the transmission equipment. The antenna design has been adapted to the most recent evolution of the interfaces, which have been modified in the last 3 years. Specific R\&D is in progress on key technologies that are required in the antenna design: joining technique between Titanium Alloy and stainless steel, copper coating method, RF contacts.

\section{Schedule and Staged Approach}

A realistic and detailed timetable up to the First Plasma, together with the associated costs, was submitted to the ITER Council in June 2016. At this $18^{\text {th }}$ session, the members of the Council have validated the elements of principle of the updated calendar submitted by ITER Organization. As a result of two years of efforts by ITER Organization and the seven domestic agencies, an integrated calendar sets the date of the first Plasma in December 2025. In November 2016, the ITER Council adopted the current complete updated calendar covering the period from now on, via the First Plasma, until the start of deuterium-tritium operations[1].

The calendar details a 4-stage approach as shown in fig. 1. First plasma is planned in December 2025 that will allow performing technical tests on the basic components of the machine: magnets, vacuum, gas, etc... At this stage, the torus will be essentially empty with very limited set of diagnostics and only part of the ECRH system ( $\max 8 \mathrm{MW}$ ), mainly to assist plasma breakdown. It will be followed by an assembly and commissioning phase leading to an 18 months experimental session (Pre-Fusion-Power-Operation-1). At this stage, the machine will be equipped with inner components, and the ECRH system will be completed to its nominal power, $20 \mathrm{MW}$. During PFPO1, planned during 2029 and first part of 2030, experiments will take place in $\mathrm{H}$ and/or He plasmas, at various levels of toroidal field (third, half and nominal). From mid-2030

Corresponding author: bertrand.beaumont@iter.org

(C) The Authors, published by EDP Sciences. This is an open access article distributed under the terms of the Creative Commons Attribution License 4.0 (http://creativecommons.org/licenses/by/4.0/). 


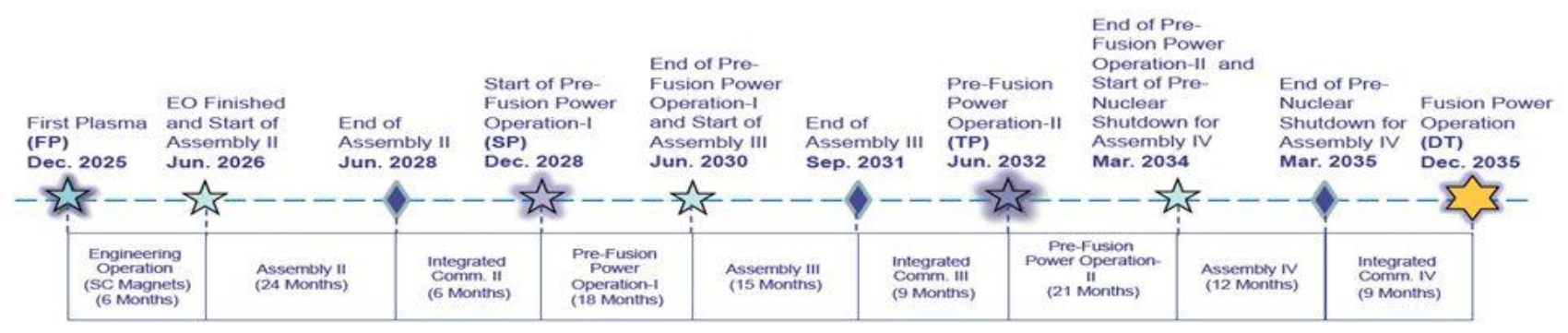

Fig. 1. Four Stages Approach from First Plasma to DT Operation

to mid-2032, the heating systems will be completed to provide the nominal heating power: $33 \mathrm{MW}$ of NNBI and $20 \mathrm{MW}$ of ICRH, together with the already existing $20 \mathrm{MW}$ of ECRH power. Experiments will follow during PFPO2 with full capacity of heating systems until March 2034, aiming to prepare for the DT operation.

It is important to note that the Council approved that the second ICRF antenna be re-integrated in the construction baseline and budget, together with the second set of power supplies that were previously deferred to the operation budget. This is a very significant and positive step: the ICRF construction baseline is now restored to its full performance, based on all components of the 20 MW system initially planned in the initial baseline.

In addition, the November 2016 Council requested that the IO, Members and their Domestic Agencies (DAs) accelerate the Neutral Beam Injection (NBI) and Ion Cyclotron Resonance Heating (ICRH) systems, making use of existing expertise in the Members and their DAs and of progress that will be achieved in the coming 2-3 years, with a view to enabling the use of the ICRH system for the PFPO1 in the interests of shortening the period from First Plasma to DT Operation. This acceleration would allow to better use the PFPO1 experimental session, and perform an earlier commissioning of the ICRF system [2].

\subsection{ICRF acceleration:}

As a consequence, the $\mathrm{IO}$ and respective DAs are investigating the feasibility of accelerating the ICRH system with a view to providing $10 \mathrm{MW}$ of ICRH power in the PFPO-1 experimental campaign.

The 4 stage approach has been developed with the inputs of the configuration workshop and the cost constraints of the DAs for the relevant procurements. Issues have been identified with advancing the delivery of some of the transmission line components, as currently the USDA cost constraints and schedule baseline are not compliant with an accelerated program. However the main critical path, to ensure $10 \mathrm{MW}$ for PFPO-1, is the antenna which is not anticipated to be ready until 2030 .

To accelerate $10 \mathrm{MW}$ of ICRH power with one antenna, so that it is available for assembly phase II, would imply that the ICRH antenna would need to be delivered to the IO site by October 2027 thus allowing for six months of testing in the Port plug test facility (PPTF) and three months for the installation, i.e. this would mean that the antenna would need to be installed and ready for the machine integrated commissioning in July 2028. Therefore, three year acceleration on the current antenna schedule (current delivery foreseen in September 2030) would be required. The evaluation of an accelerated path is in progress and will be reported at the next IC-21 and include the possible solutions for a three year accelerated schedule. A final report will then be made available at the IC-22 in June 2018 and will include the full risk assessment and required additional budget and resources for the acceleration.

A late installation during a short shutdown during PFPO1 is also an alternative to be considered.

\section{ICRF system progress}

\subsection{HVPS and RF Sources}

ITER India is responsible for the procurement of the RF Sources and part of the corresponding power supplies to be installed in the RF building. ITER India has initiated a voluntary R\&D program for establishing the technology prior to prototype and series production. This R\&D is motivated by the demanding performance requirements set upon the ITER RF sources when compared to the state of the art. Only two potential suppliers are able to provide high power RF tubes that could be suitable for ITER: CPI in the USA and TED in Europe. Table 1 provides typical demonstrated capabilities against ITER needs.

Table 1. Comparison between ITER specifications and typical values from Industry

\begin{tabular}{|c|c|c|}
\hline ITER Specifications & $\begin{array}{c}\text { Tetrode } \\
\text { CPI }\end{array}$ & $\begin{array}{c}\text { Diacrode } \\
\text { TED }\end{array}$ \\
\hline $2.5 \mathrm{MW}$; VSWR 2:1; & $\sim 1.9 \mathrm{MW} ;$ & $1 \mathrm{MW} ;$ \\
$2000 \mathrm{~s} ; 35-65 \mathrm{MHz} ;$ & VSWR 1:1 & $\begin{array}{c}\text { VSWR 1:1 } \\
1000 \mathrm{~s} ;\end{array}$ \\
\hline $\begin{array}{c}3.0 \mathrm{MW} ; \text { VSWR 1.5:1; } \\
2000 \mathrm{~s} ; 40-55 \mathrm{MHz}\end{array}$ & $\begin{array}{c}300 \mathrm{~s} ; \\
\mathrm{MHHz}\end{array}$ & $200 \mathrm{MHz}$ \\
\hline$\eta \sim 50 \%-60 \%$ & $>60 \%$ & $>60 \%$ \\
\hline $\mathrm{BW}+/-1 \mathrm{MHz} @ 1 \mathrm{~dB}$ & $\begin{array}{c}\text { High Q } \\
\text { cavity }\end{array}$ & $\begin{array}{c}\text { High Q } \\
\text { cavity }\end{array}$ \\
\hline
\end{tabular}

One of the important specifications is the ability to deliver a constant output power even with VSWR up to $2: 1$ for any phase of the reflection coefficient, corresponding to $11 \%$ of reflected power. ITER will then be equipped with a set of robust RF sources. 
The ITER RF source layout consists of two parallel three-stage amplifier chains, with a combiner circuit on the output side. This kind of RF source is unique in terms of its stringent specifications. The R\&D program in India is aiming to select the supplier for the driver and end-stage of the three-stage amplifier chain. In this program, both technical solutions proposed by suppliers will be installed in a test facility in IPR: the suppliers have designed and fabricated driver and final stage amplifiers, and tests have been performed according to the possibilities of the test equipment in factories. In the ITER India test facility, these are powered by a solid state pre-driver (10 kW typ.) provided by ITER India, and deliver the RF power in a $3 \mathrm{MW}$ dummy load (Fig. 2 ), that can be detuned for testing on high VSWR (fig. 3). Full power and long duration tests can be performed on various loading conditions [3].

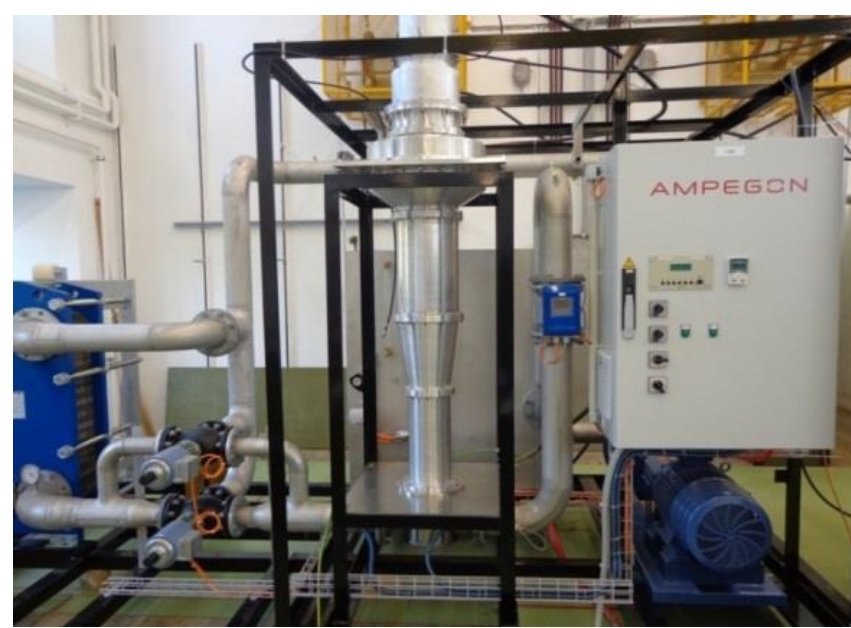

Fig. 2. High Power $3 \mathrm{MW}$ matched load at IPR

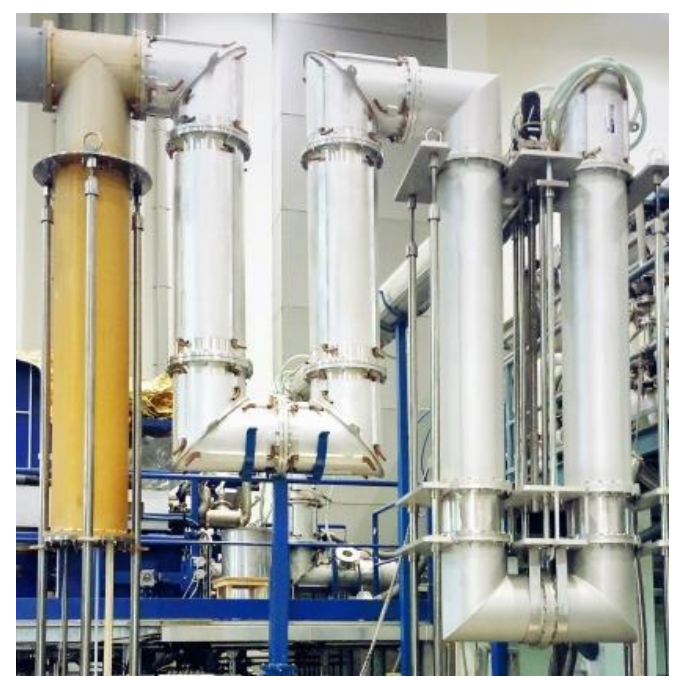

Fig. 3. Stub and phase shifter for high VSWR tests at IPR

For the Diacrode-based system, the entire system has been stabilized against parasitic oscillation before powering the amplifiers up to the $1.5 \mathrm{MW}$ level at various frequencies from 35 to $65 \mathrm{MHz}$ for 2000 s pulses [3]. A further test has been performed for $1.7 \mathrm{MW} / 3600 \mathrm{~s}$ at $36 \mathrm{MHz}$ as extended operation (Fig. 4).

The tetrode based system is now also installed in the RF test facility and tests are performed at different power levels, frequencies, and VSWR in preparation of final site acceptance tests.

Both proposals experience instabilities on the band edges near 35 and $65 \mathrm{MHz}$, but these frequencies are well out of the ITER required range: 40 to $55 \mathrm{MHz}$.

The tests will conclude if one or both proposals meet the specifications required for ITER, and will determine the voltage requirement for the anode driver, which is fed by an intermediate tap point in the high voltage power supply.

The tests in ITER India are also used to validate the HVPS design and its integration, and interaction, with the RF source: a fast switch off and a low stored energy helps to keep the dissipated energy low to protect the vacuum tube in case of arcing.

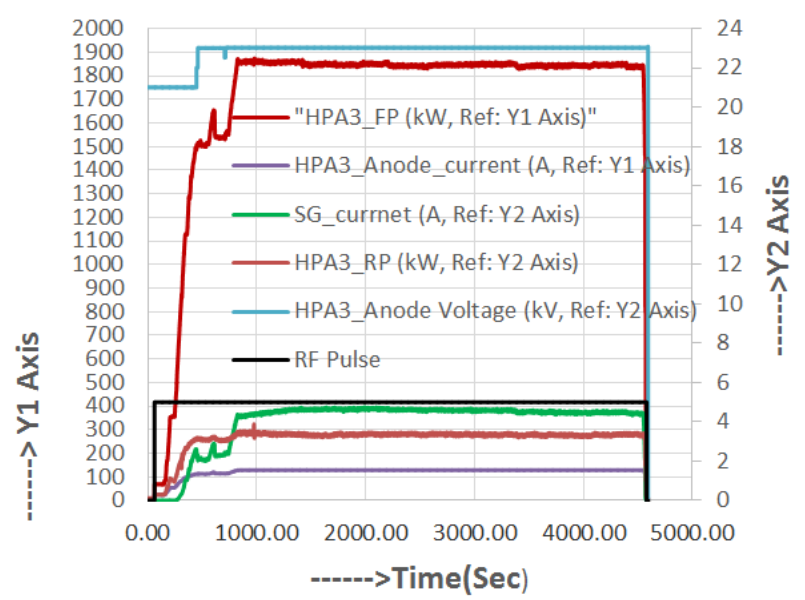

Fig. 4. 3600 s high power shot with Diacrode based system; HPA3 $=$ end stage.

The combiner prototype circuit is also being tested at various levels of power and duration.

Once the tests are completed and the final series supplier is selected, the preliminary design of the RF sources will be reviewed to IO, and the contract will be placed by ITER India for the procurement of the series of amplifiers, auxiliaries and high voltage power supplies.

\subsection{Transmission lines and matching system}

The transmission lines and matching system are procured by USIPO (the US Domestic Agency) and will be installed in the RF, Assembly, Tokamak and Hot Cell buildings. It is a large network with around $1100 \mathrm{~m}$ of $300 \mathrm{~mm}$ diameter rigid coaxial lines and approximately $30090^{\circ}$ elbows.

The layout in the RF building allows interconnecting the $\mathrm{RF}$ sources with the 8 main transmission lines, the 2 power dummy loads and the test line connected to the Port Plug Test Facility in the Hot Cell Facility. By means of 4 port coaxial switches (Fig. 5 \& Fig. 6), the source \#9 can replace any faulty source among \#1 to \#8, while that faulty source is connected to a power dummy load for maintenance.

The port cell equipment layout is still a matter of concerns: Remote handling have imposed large permanent structures in the cells that are not compatible with the initial proposal of a 3 stubs pre-matching system. A revised configuration based on 2 stubs for 
each line is considered, with reduced frequency range [5].

USIPO is developing a large test program to validate technical choices as well as potential suppliers for each type of components. Standard coaxial support using 3 quartz rods has been already chosen [5], and the most recent tests focus on hybrid splitters and 4 port switches (Fig. 5 \& Fig. 6).

Test rating is corresponding to levels up to $6 \mathrm{MW}$ power handling (typically $37 \mathrm{kV}$ with $42 \mathrm{kV}$ transients in $50 \Omega$ components, with pulse duration of one hour. These specifications cover the ICRF upgrade case: transmission equipment in the tokamak building is then compatible with the increase to $40 \mathrm{MW}$ of the ICRH system, and thus do not require modifying the transmission system installed in the nuclear building.

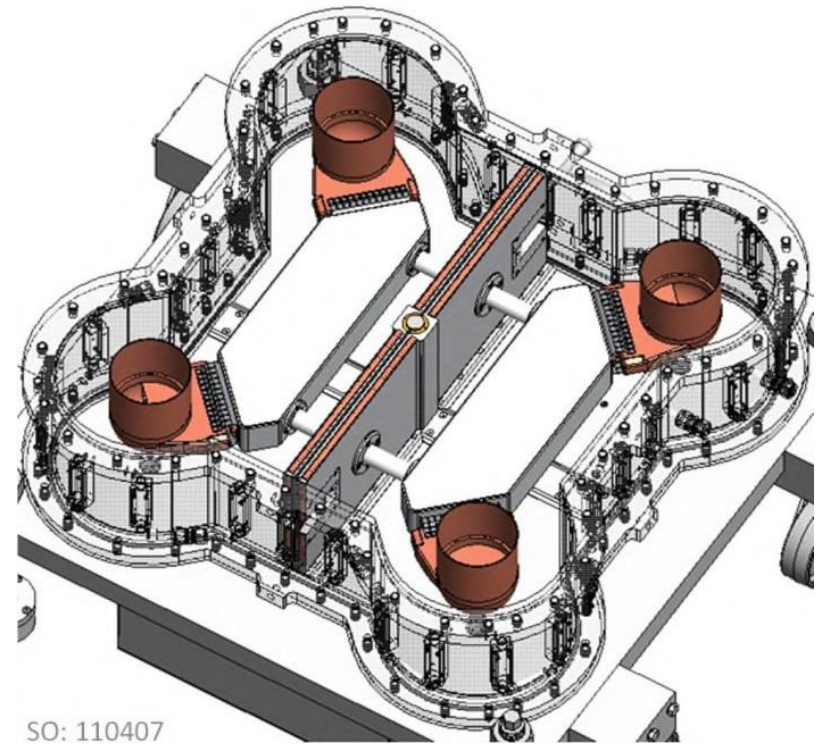

Fig. 5. Cut-away view of 4-port switch enabling connections 2 by 2

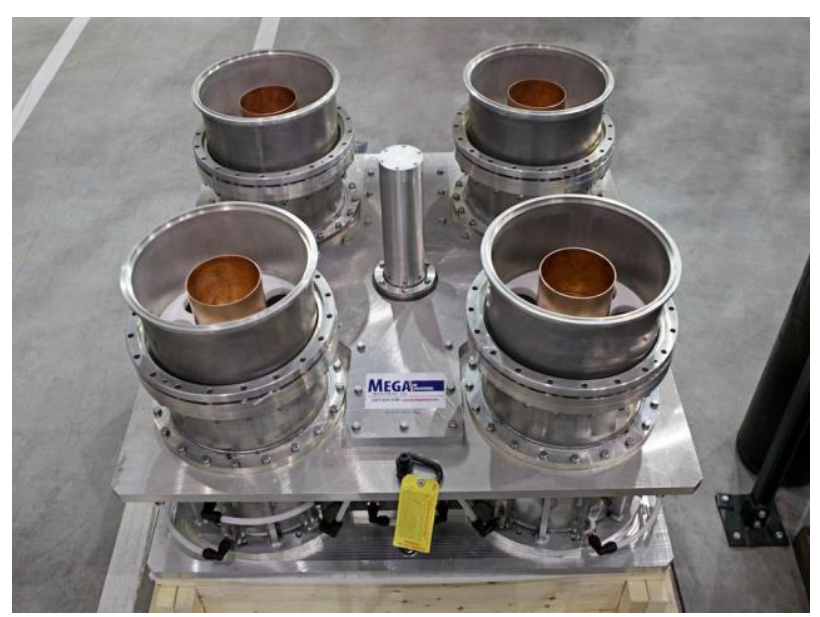

Fig. 6. Test article of 4-ports switch

Structural analysis of current lines layout is used to establish loads for main line components. These components will be reviewed by IO in September 2017 in order to prepare the first bulk orders for series of straights, elbows, 3MW load and auxiliary equipment. The first deliveries are needed for the RF source testing that should take place in RF building in 2020-2025.

\subsection{Antenna system}

The antennas are installed in equatorial ports \#13 and $\# 15$. The environment has evolved in the past 3 years and the antenna design that was approved at the Preliminary Design Review in 2013 needs to be modified.

The front face cross section is reduced to accommodate the blanket modules final design and provide realistic gaps. The port plug structure is modified to allow proper tolerance with port extension and wider gaps during installation, to provide location for skids used during installation, to accommodate the sealing flange system and to provide gripping points for the remote handling interface.

In addition, the back flange of the antenna is simplified by moving some components away from the antenna or by reconsidering the shimming requirements, and the rear bulkhead position has been shifted toward the plasma to allow more space at the back of the antenna.

The design evolution ensures compatibility with interfaces and simplifies the shimming concept which allows adjusting the radial position of the RF modules (and thus the strap/plasma edge distance).

Cover plates to protect the antenna back flange from contamination during cask transfer and hot cell refurbishment provide provision for access to Removable Vacuum Transmission Lines (Fig. 7). Each individual RVTL can be accessed and replaced through a hatch, while the rest of the antenna back flange stays protected from the hot cell workshop environment.
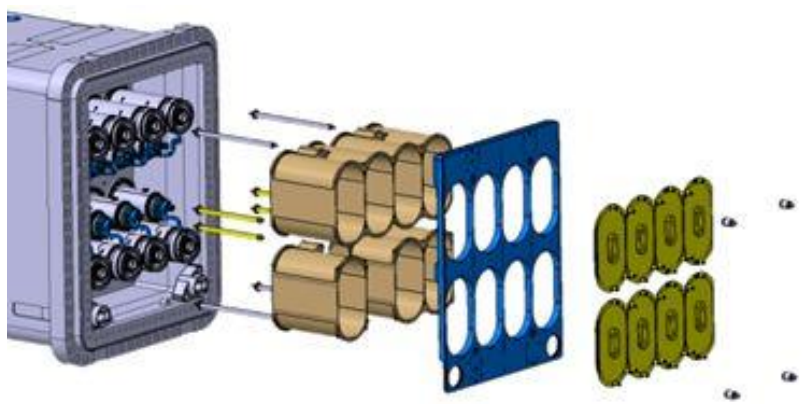

Fig. 7. Cover plate system to limit contamination of antenna backplate; individual plates provided to access each RF input

The design of a set of hot cell tools is progressing: a main frame (Fig. 8) holds the antenna itself and provide handling points for lifting and tilting. A lifting tool is used to catch the front of the RF module and extract it from the plug structure, and guiding tools are used during assembly phases in the hot cell workshop. 


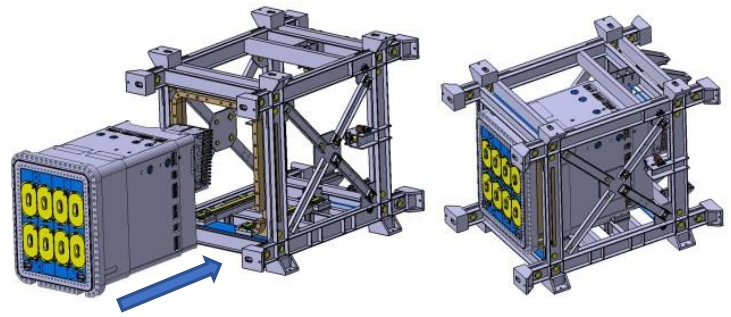

Fig. 8: Handling frame (14 t) for IC antenna Port Plug (45 t)

A numerical model for structural analysis has been developed to assess the driving load cases that will be used to develop the final design. Future analysis work will be completed by using a master model and sub structuring approach (Fig. 9 \& Fig. 10).

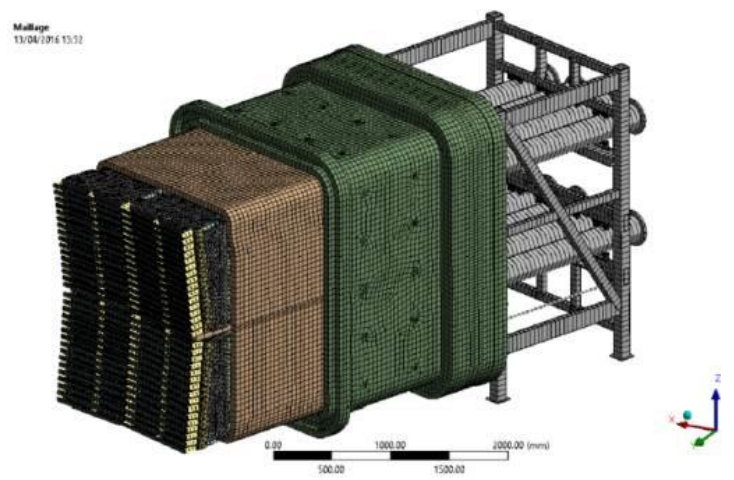

Fig. 9 Antenna model for structural analysis ( $>3$ million nodes)
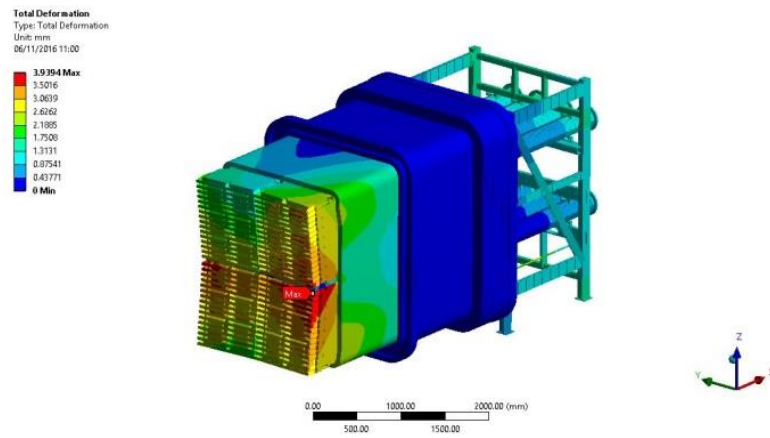

Fig. 10. Typical load case (VDEII): 4 mm max.displacement.

The design work is performed under a task agreement with F4E and is reactivated from this new antenna configuration.

In parallel, $\mathrm{R} \& \mathrm{D}$ activities are in progress.

High heat flux tests of Faraday Shield elements have been reported earlier [5]. A real size Faraday shield mock up is planned to be built to test manufacturing process.

Copper coating is used to reduce RF losses on antenna transmission lines. Two methods have been considered: 1) Galvanic coating on the titanium alloy used in the vacuum transmission lines has exhibited issues of adherence and reproducibility: composition, purity of bath, process control do not guarantee stable results. 2) Cold spraying has been investigated and gives promising results: adherence to substrate is good as well as compatibility with the high temperature brazing cycle. The method uses a robotic arm driving a spraying gun (Fig. 11). The surface is prepared by thorough cleaning and sand blasting using alumina grit, then the copper powder is sprayed at high velocity on the titanium. The gas pressure and gas temperature have a large influence on the deposition efficiency, coating thickness and quality of the deposited coating. The resulting coating can be thick, up to few tenths of a mm, and reworked (machining or polishing). Coating purity is high and the electrical conductivity is in the range of 85 to $90 \%$ IACS. Successful tests have been performed for outer surface of inner conductors as well as inner surface of outer conductor. Samples submitted to Ticusil brazing cycle have confirmed no significant loss of adhesion and no creation of blisters.
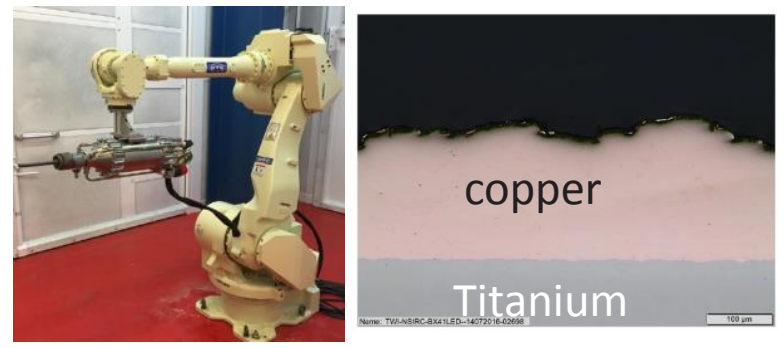

Fig. 11. Robotic arm for cold spray; micrographic view of coating

The RF window is a critical element of the antenna; it is part of the confinement boundary. The design uses titanium alloy rings brazed to ceramic cones. Differential expansion between metal and ceramic is used to induce a compressive stress on the ceramic during cooling down of the brazing process. The initial proposal at PDR is to build all vacuum transmission line in titanium alloys, but the transition to the stainless steel cooling circuit was not defined in that initial proposal. It is now foreseen to keep Ti alloy only were it is necessary, i.e. to join the ceramic, and to perform a transition to stainless steel parts as near as possible to the ceramic windows. This strategy allows using conventional welding techniques to build the transmission lines, but requires joining stainless steel to Ti alloy. The joint will have to survive high temperature ceramic brazing cycle, and be compatible with water cooling near the ceramic edges. Two techniques are being investigated: rotary friction weld and uniaxial diffusion bonding. Both joints are performed without fusion of the metals, a solid state process, to avoid degrading the material properties.

Metallic interlayers are used to facilitate bonding and prevent the formation of brittle phases between dissimilar materials (Fig. 12). Niobium, Copper, Nickel, Vanadium and Zirconium are investigated in test samples. Tests are in progress for friction weld and will start soon for uniaxial diffusion bonding. Figure 11 shows a cut through the joint for test between $316 \mathrm{~L}$ and Niobium. In that test, the weld was not successful. The other example shows a good weld between Zirconium and Ti grade 5 . 


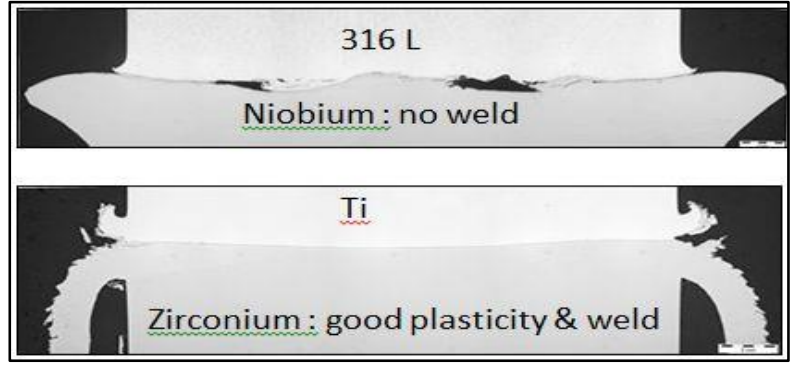

Fig. 12. Early tests of rotary friction welds with interlayer

The tests have discarded $\mathrm{Nb}$ and $\mathrm{V}$, and now concentrate on $\mathrm{Zr}$ to optimize the friction weld parameters. In parallel, the uniaxial diffusion bonding contract is about to be launched.

RF contacts are used in the antenna to ensure electrical continuity while providing mechanical compliance. They also allow assembly of vacuum transmission lines to antenna structure and RF modules. Contacts are critical components of the antenna design: they need to withstand high currents up to $6 \mathrm{~A} / \mathrm{mm}$, be resistant to long baking cycles, and ideally to the full life cycle of the antenna representing 30000 mechanical cycles. Several designs have been proposed and tests are performed in CEA/IRFM laboratory for RF vacuum tests and in CEA/SDTC for sliding tests in relevant conditions [7]. As of today, the Multi-Contact ${ }^{\circledR}$ LA-CUT/0,25/0 have been tested up to $50 \%$ of the required current. It is a special version in a $\mathrm{CuCrZr}$ alloy that would resist creeping during long baking period at $240^{\circ} \mathrm{C}$. Further tests are necessary with optimized geometry and improved cooling in order to raise the current limit.

\subsection{Plant Control system}

IO team is in charge of the ICRF plant control system that will interface CODAC with the local control units controlling HVPS, RF sources, transmission lines and antennas, delivered by each DA.

This plant control system is in final design phase. A prototype is installed and tested on real hardware within the CODAC lab in IO, with 2 PLCs (CPU-400 station and SM-300 IO Modules) and 2 fast controllers with PXI components (Chassis \& IO Modules). IC-PSC function configuration and communication tests are performed to check data exchange between the different levels, and to validate the best architecture.

\section{Conclusion}

The overall schedule recently agreed by the ITER Council gives the path for staged installation of ITER components. The ICRF system is due to deliver power in plasmas in 2032, but an earlier installation is considered for plasma experiments from 2029. The subsystem development is progressing well with good results of HVPS and RF source testing in India, of RF transmission line and layout studies in US, and antenna design and $\mathrm{R} \& \mathrm{D}$ in EU.

\section{References}

1. ITER Council Press release : http://www.iter.org/doc/www/content/com/Lists/list items/Attachments/708/2016_11_IC-19.pdf

2. "ICRF scenarios for the ITER non-active phase ", Mireille Schneider, this conference (to be published)

3. "Progress in High Power Test of R\&D Source for ITER ICRF system", A. Mukherjee, 26th IAEA Fusion Energy Conference (FEC-2016), 17-22 OCT 2016, Kyoto, Japan

4. "THALES Electron Devices activities for ITER and satellites projects in plasma heating solutions Recent results", Stéphane Bethuys, this conference

5. "Status of the ITER Ion Cyclotron Heating and Current Drive System", P.Lamalle et al., AIP Conference Proceedings;2015, Vol. 1689 Issue 1

6. "Developments in the Testing of ITER Ion Cyclotron Transmission Line Components", R.G. Goulding, this conference

7. "RF Characterisations of High Current Steady-State Sliding Contacts for the ITER ICRH Antenna", J.Hillairet, this conference

\section{Disclaimer}

The views and opinions expressed herein do not necessarily reflect those of the ITER Organization. 